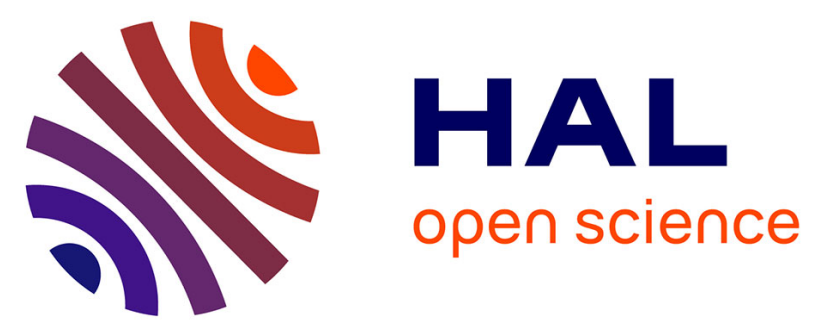

\title{
Impact of IEC 61850 GOOSE Communication Quality on Decentralized Reactive Power Control in Smart Distribution Grids - a Co-simulation Study
}

Thijs Peirelinck, Antoneta Iuliana Bratcu, Yvon Besanger

\section{- To cite this version:}

Thijs Peirelinck, Antoneta Iuliana Bratcu, Yvon Besanger. Impact of IEC 61850 GOOSE Communication Quality on Decentralized Reactive Power Control in Smart Distribution Grids - a Co-simulation Study. EPEC 2016 - IEEE Electrical Power and Energy Conference, Oct 2016, Ottawa, Canada. hal-01347640

\author{
HAL Id: hal-01347640 \\ https://hal.science/hal-01347640
}

Submitted on 5 Oct 2016

HAL is a multi-disciplinary open access archive for the deposit and dissemination of scientific research documents, whether they are published or not. The documents may come from teaching and research institutions in France or abroad, or from public or private research centers.
L'archive ouverte pluridisciplinaire HAL, est destinée au dépôt et à la diffusion de documents scientifiques de niveau recherche, publiés ou non, émanant des établissements d'enseignement et de recherche français ou étrangers, des laboratoires publics ou privés. 


\section{Impact of IEC 61850 GOOSE Communication Quality on Decentralized Reactive Power Control in Smart Distribution Grids - a Co-simulation Study}

\author{
Thijs Peirelinck \\ Grenoble Institute of Technology \\ Grenoble Images Speech Signals \\ and Control Laboratory (GIPSA-Lab) \\ 38402, Saint-Martin d'Hères, France \\ thijspeirelinck@gmx.com
}

\author{
Antoneta Iuliana Bratcu \\ Grenoble Institute of Technology \\ Grenoble Images Speech Signals \\ and Control Laboratory (GIPSA-Lab) \\ 38402, Saint-Martin d'Hères, France \\ antoneta.bratcu@gipsa-lab.fr
}

\author{
Yvon Bésanger \\ Grenoble Institute of Technology \\ Grenoble Electrical Engineering Laboratory \\ (G2ELab) \\ 38000, Grenoble, France \\ yvon.besanger@g2elab.grenoble-inp.fr
}

\begin{abstract}
Smart grids are expected to increase efficiency, reliability and sustainability of future energy usage. Employing stateof-the-art information and communication technologies within power grids, is defining for smart grids; therefore interaction between energy grids and communication networks requires thorough study. Combined simulation of the behaviour of the electrical and communication network would allow to analyse their influences on one each other.

In this paper, the results of a MATLAB $^{\circledR} /$ Simulink $^{\circledR}$ cosimulation of an electrical distribution grid containing two renewable sources in interaction with its communication network are presented. Communication between different nodes is based on the IEC 61850 GOOSE protocol, whose simulation model incorporates its different efficiency and reliability features. Communication network and electrical grid are modelled using SimEvents ${ }^{\circledR}$ blocks and SimPowerSystems ${ }^{\circledR}$ blocks, respectively. The effect of perturbations on the reliability of the data transfer links, while information to perform decentralised reactive power control is flowing on them, is examined.

Index Terms-Co-simulation, Generic Object-Oriented Substation Event (GOOSE), IEC 61850, Reactive power control
\end{abstract}

\section{INTRODUCTION}

The energy sector faces many challenges, one of them is the need to allow integration of Distributed Energy Resources (DER) in the electrical grid. However, for this to be successful, grid operators will have to extensively use Information and Communication Technology (ICT) and, have to expand the communication network drastically and rapidly. Only the combination of electrical grids and communication networks will allow challenges to be overcome and the 'smart grid' to be truly smart [1].

The merger of electrical grids and communication networks leads to an increasing reliability of the electrical grids stability on the communication networks performance. Since communication channels are not perfect, simulations will have to show these interdependencies [2]. The nature of electrical dynamics

This work was partially supported by the CNRS (Conseil National de la Recherche Scientifique, France) grant within the framework of CYBERGRID Exploratory Project. and communication system events is completely different, and they should thus be treated differently in simulations. Electrical dynamics are time-driven, whereas a communication system is event-based. Because of these contrasting features, they cannot simply be combined into one single piece of software. Experts have been trying to combine popular tools, including MATLAB ${ }^{\circledR} /$ Simulink $^{\circledR}$, with each other to ideally converge to a single platform able to simulate both networks [3]. Advanced mechanisms were developed in order to ensure correct coordination between the two simulation tools, since they were not designed to cooperate [4].

Real-life examples of the usage of co-simulation and cyberphysical networks exist. The Wide Area Control System (WACS), using IEC 61850 GOOSE on a Wide-Area Ethernet network, to enable communication between three substations in Australia, is only one example [5].

The combination of an electrical grid and a communication network provides the ability for highly automated control. An example of an ancillary service, which can be provided if DER are able to communicate with each other, is distributed reactive power support for voltage control [6]. Two main approaches are seen in literature: the centralised [7] and decentralised [8] approach, respectively. Using the communication grid, static voltage control based on load predictions, can easily be changed in a more dynamic automated control system.

Cyber-physical systems, with highly efficient and reliable communication protocols, allow for Advanced Distribution Automation (ADA) systems to react on real-time changes without human intervention. But, in order to understand the interdependencies, co-simulation of the event-based communication, and its effects on the time-driven electrical grids, is necessary. In this paper, a single software environment, which is MATLAB $^{\circledR} /$ Simulink ${ }^{\circledR}$, accommodates simulation models of both communication and electrical network, namely SimEvents ${ }^{\circledR}$ toolbox for the communication system and SimPowerSystem ${ }^{\circledR}$ toolbox for the electrical system. The effect of perturbations within the communication network, which is providing services for reactive power control, was 
implemented and assessed by simulation. Simulation models within the same software environment are expected to ease formal mathematical description.

The paper is organised as follows. Section II reviews the literature dedicated to IEC 61850 GOOSE. Section III reveals the adopted communication network configuration, whereas the electrical grid configuration is given in Section IV. The different scenarios simulated and their corresponding results are analysed in Section V. Finally, in Section VI, the conclusions are formulated and further work issues are presented.

\section{IEC 61850 GOOSE FEATURES AND LITERATURE REVIEW}

GOOSE was intended to be a communication protocol used within the substation automation process. However, as it advanced in time, it became much wider and was used in other applications as well. The International Electrical Commission (IEC) proposed three main goals for the 61850 standard [9].

1) Intelligent Electronic Devices (IEDs) manufactured by different companies should be able to communicate with each other.

2) In order to allow further development a certain degree of freedom has to be available to the manufacturers.

3) Further development will lead to progress. The standard should always allow for this to happen and keep on track.

GOOSE is one of the communication protocols within the IEC 61850 standard. The main focus of this paper is on modelling the GOOSE protocol most relevant features and functions. GOOSE main purpose is to enable lateral communication between IEDs. A visual representation of the position of GOOSE within a substation can be seen in Fig. 1.

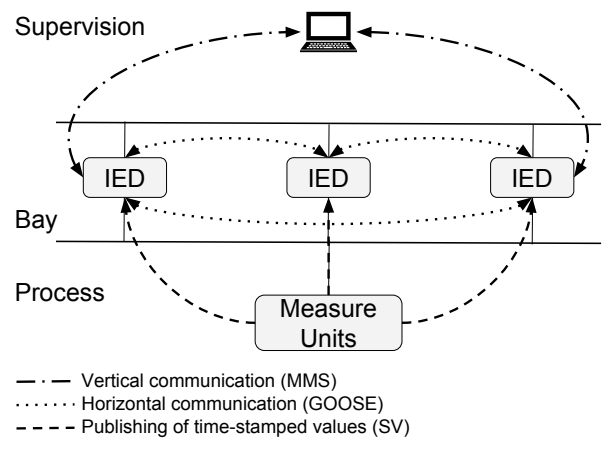

Fig. 1. GOOSE within the IEC 61850 family.

GOOSE is mainly responsible for fast real-time and timecritical services. Therefore it needs to be efficient and, with less importance, reliable. To achieve this, GOOSE is a multicast, publisher/subscriber, unconfirmed communication protocol which is directly operating on Ethernet. These different properties all have their advantages and allow the protocol to be very useful in different scenarios [10].

- Multicast: because the adaptation of multicast communication within the GOOSE protocol, multiple IEDs can

\begin{tabular}{|l|l|c|c|c|c|c|c|}
\hline Preamble & SFD & $\begin{array}{c}\text { Dest. } \\
\text { Address }\end{array}$ & $\begin{array}{c}\text { Source } \\
\text { Address }\end{array}$ & TAG & Type & PDU & FCS \\
\hline
\end{tabular}

Fig. 2. Ethernet frame

receive the same data at the same time. This allows for fast and non-redundant communication;

- Publisher/Subscriber \& Unconfirmed: enables less redundant communication, since establishing a connection between two communicators is unnecessary, which is beneficial for the speed;

- Directly operating on Ethernet: ethernet is a widespread technology, prone to constant development. As Ethernet will evolve, this progress will also be reflected to GOOSE. Moreover, the advanced functionalities of Ethernet can easily be used. For example, the priority tagging functionality of Ethernet frames can be used efficiently within the GOOSE protocol.

\section{A. GOOSE Frame}

Since GOOSE is operating directly on Ethernet, the frame structures are very similar. A visual representation of such a frame is shown in Fig. 2. The different components of this frame, will shortly be explained [10].

- Dest.- \& Source Address: these bytes represent the destination and the source MAC-address. Since in GOOSE a message is always sent in a multicast fashion, the destination will be the multicast address;

- Tag: part of this tag is the priority Virtual Local Area Network (VLAN) ID, GOOSE frames can skip the queues that arise at switches, or they can get ahead of other GOOSE frames within a queue, using this ID;

- Ethertype: The Ethertype 2-byte part of an Ethernet frame is used to show which communication protocol is encapsulated within this frame;

- Protocol Data Unit (PDU): This part of the frame contains the actual data along with some useful metadata;

- Frame Check Sequence (FCS): This part of the frame is a value calculated based on the data and allows for the receiving IED to check if the data was prone to errors during transmission.

\section{B. Retransmission Mechanism}

The reliability of GOOSE communication is not ensured by acknowledgements, instead a retransmission mechanism is used. Every frame sent by an IED is repeatedly sent as long as the state of that device did not change. By increasing the amount of times a frame is sent, the chance of arriving will rise.

This retransmission mechanism can be explained more clearly based on Fig. 3. The system is in the first state when nothing is happening, and in the second state when an event took place. In the first state, the retransmission mechanism will make sure that every $T_{\max }$ seconds, the same data will be sent. This way, some of the retransmissions can get lost, or be prone to errors while travelling, but the receiver will 


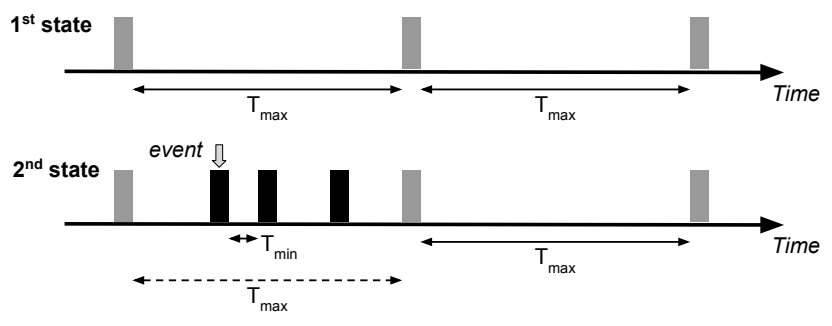

Fig. 3. Retransmission mechanism.

have the correct information in the end. In the second state the data changes and the new data will be sent. After a short amount of time $\left(T_{\min }\right.$, with $\left.T_{\min }<T_{\max }\right)$ the data will be sent again. This will happen a couple of times more, but every time with an increased retransmission interval. The interval will increase steadily until it reaches the same length as $T_{\max }$, after which the system is in the first state again. Next, the retransmissions happening in the second state will be referred to as 'fast retransmissions'. The length of these intervals can be chosen by the manufacturers [11].

\section{IMPLEMENTATION OF IEC 61850 GOOSE}

A simple communication network implementing the IEC 61850 GOOSE protocol was considered. Since GOOSE is a highly advanced communication protocol with a lot of functionalities outside the scope of this paper, a simplified version was implemented. Hence, the communication network consists of IEDs and a switch, whose main functionality is the routing of the data frames to the correct receivers. In what follows, the functionality of these devices and the protocol implemented by using blocks of the SimEvents ${ }^{\circledR}$ toolbox in MATLAB $^{\circledR} /$ Simulink $^{\circledR}$, will be explained.

\section{A. Physical devices}

- IED: an IED can have different implementations according to its requirements. The requirements of the implemented IEDs are just sending and receiving data. The sending part holds a register with the current dataset. Connected to this register are the retransmission timers. These timers will create a trigger, which will initiate the creation of an event and an entity. The sending part of the IED also adds the necessary attributes: the data, the source address, the destination address (multicast address) and the VLAN Identifier (V-ID). The receiving part is slightly more complicated. The source MAC-address of the entity arriving from the switch will be read by the receiving IED. For each sending IED it wishes to retrieve data from, it will have a receiving register. Based on the source address, the receiving IED will decide in which register the data have to be stored. Before the entity arrives at the register though, it will pass through a FIFO buffer. This will allow for multiple entities to be buffered. When a read signal is given, the data attribute of the first entity in the FIFO will be read and will be put into the register;

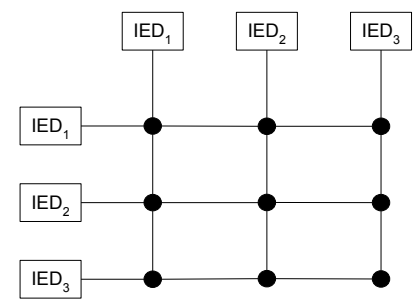

Fig. 4. Internal connections of the switch.

- Switch: the switch tasks consist of routing the packets to the correct IEDs, buffering arriving packets and detecting collisions of packets. In this network, three IEDs are communicating with each other, therefore, the switch will have three ports. These ports are internally connected with each other as in Fig. 4. Based on the subscription table and the source address the switch is able to decide to which ports the arriving entity needs to be forwarded. The first row of the subscription table consists of the subscriber IEDs, whose subscription is given on the corresponding column in the second row. This means that for every subscriber-subscription-pair there is one column in the table. In a real-life implementation of GOOSE this table is dynamic and IEDs can add and/or delete subscriptions in real-time. However, this functionality is not really needed in this case, since it is assumed that the electrical network configuration will never change. Thus, the subscription table is implemented as a static table.

The switch also performs collision detection. All the arriving packets will come together in a priority queue, in which the packets will be sorted by their corresponding priority (based on the V-ID).

Based on [12] the delay inside the switch is equal to 5.2 $\mu s$, existing due to finding the subscription in the lookup table and priority queue buffering. Any packet can be subject to an additional delay based on the time it needs to spend inside the buffer.

\section{B. Protocol}

The protocol makes sure there is a standard way of communication between the IEDs, and that the switch can find the necessary information within every frame. Its operating features can be divided into three main parts.

1) Multicast: all the IEDs are able to communicate with all the other IEDs. An IED just sends the data once, not knowing who will receive it, and the switch duplicates the frame while making sure only the IEDs that actually want the data get them;

2) Event-based: if the data change, the communication chain is started;

3) Retransmission: the two most important implementation characteristics of this mechanism are the two retransmission timers held by the IEDs. As soon as a dataset is communicated for the first time, these will be reset. The first timer will make sure the packet gets sent in 

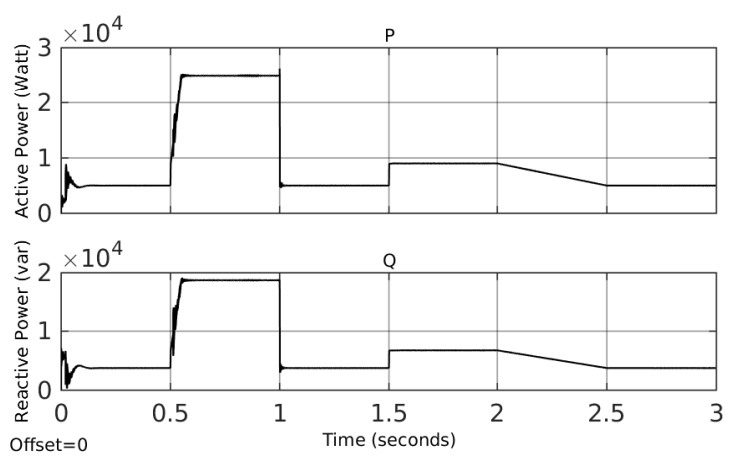

Fig. 5. Electrical load.

a predetermined interval, called $T_{\max }$ in the literature. The second timers responsibility is the so-called 'fast retransmissions' mechanism. This makes sure that after new data are sent it will send the same data quickly again. When the chance of non-reception is reduced because of the fast retransmissions, this will stop and the other timer will only send the data once in a while (interval $T_{\max }$ ). The values of these parameters used in the simulations are $10 \mathrm{~ms}$ and $200 \mathrm{~ms}$, for $T_{\min }$ and $T_{\max }$ respectively.

\section{ElectricAl GRID}

The distribution grid consists of a Low Voltage (LV) feeder with three load buses. Every bus consists of a 3-phase load, and two buses have a distributed generating source connected to it, one a Photovoltaic (PV) system and the other one a small wind turbine. Details about these energy production units will be provided later. Both loads at the energy nodes are constant at $12 \mathrm{~kW}$, with a power factor of 0.95 . The main load on the third bus has a more industrial nature, with a power factor of 0.8 . Its profile can be seen in Fig. 5, the voltage at this point is called $V_{\text {load }}$ (Fig. 6). This bus will be referred to as 'the load'. The bus with the PV system attached will just be referred to as the 'PV system' and similar for the 'wind turbine'.

The distribution grid is connected to a Medium Voltage (MV) grid with a $400 \mathrm{~V} / 20 \mathrm{kV}$ 3-phase $Y / \Delta$ transformer $(160 \mathrm{kVA})$. The MV grid is modelled by a perfect $50 \mathrm{~Hz}$, three-phase voltage source. Every branch has a set of mutual inductances and line resistances.

\section{A. Power Generating Units}

The PV system is implemented by means of a detailed model [13], to which a reactive power control loop was added. This PV system consists of a PV array, a MPPT regulated boost-converter (average model) and an average model of a Voltage Source Converter (VSC) (converting 500V DC to $260 \mathrm{~V} \mathrm{AC}$, represented by an equivalent voltage source). The VSC has a sample time of $0.1 \mathrm{~ms}$. A capacitor bank filters out the harmonics produced by the VSC. The PV array consists of 7 parallel strings of 5 series-connected PV modules, having a total maximum power of $10.7 \mathrm{~kW}$ at the reference irradiance value, $1000 \mathrm{~W} / \mathrm{m}^{2}$. The irradiance curve used as an input for the PV array was obtained by quarter hourly

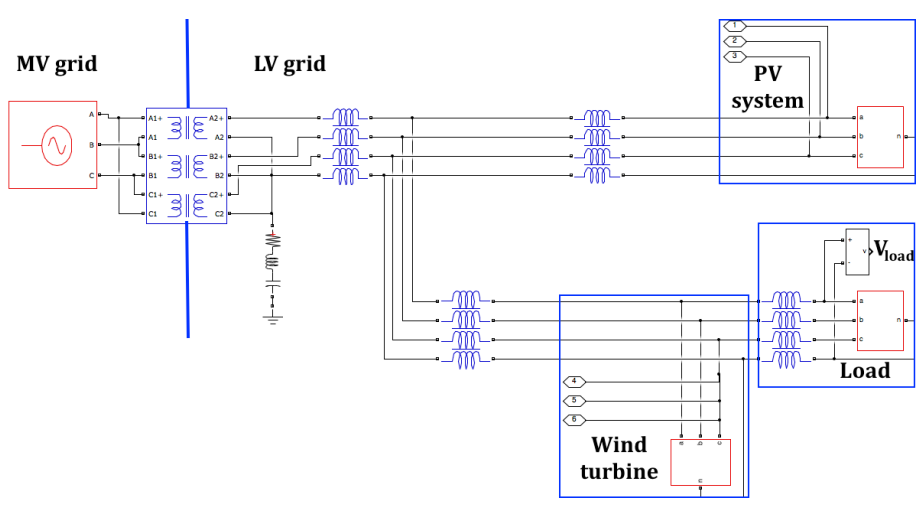

Fig. 6. Electrical grid.

measurements from a real production unit in France. However, for simulation reasons, the 24-hour period of the measurements was mapped to a span of 3 seconds, which corresponds to very fast irradiance variations.

The wind turbine was modelled by a dynamic load. Based on real measurements of a wind turbine in France, the power curve that this source is generating was determined. The measurements of one day were also scaled to only take 3 seconds. The obtained generated power by the wind turbine has the same order of magnitude as the PV system. The reactive power of the load is externally controllable.

\section{B. Reactive Power Compensation Algorithm}

A simple algorithm was developed and implemented, to illustrate the principle of reactive power control. A flowchart of this algorithm is shown in Fig. 7, with $S_{\text {in }}$ and $S_{\text {out }}$ the incoming and outgoing signal respectively and $Q_{\text {thresh }}$, arbitrary chosen to equal 9.5 kVAR.

\section{REsults}

Since both the communication network model and electrical grid model are implemented in MATLAB ${ }^{\circledR} /$ Simulink $^{\circledR}$, it is possible to simulate them at the same time and inspect their interactions. Three test cases will be investigated. First, a scenario in which all the communications work, without disturbances. Secondly, a situation where the link used to send the power reference is highly disturbed. A third scenario, simulating high disturbances on the whole communication network and their effects on the electrical grid, is analysed.

\section{A. No communication disturbances}

According to the reactive power control algorithm, the PVsystem will generate 4/3th of the reactive power reference received from the load, noted by $Q_{r e f}$ (Fig. 5). Its reactive power generation curve can be seen in Fig. 8a. However, between second 0.5 and 1 the power reference received is higher than $Q_{\text {tresh }}$ and the PV system will thus ask for help of the wind turbine. In Fig. 8b it can seen that the wind turbine successfully starts generating $2 / 3$ th of the power reference received. The PV system will, during this interval, reduce its generated power to 2/3th of $Q_{\text {ref }}$ as well. This results in $V_{\text {load }}$ as shown in Fig. 9. 


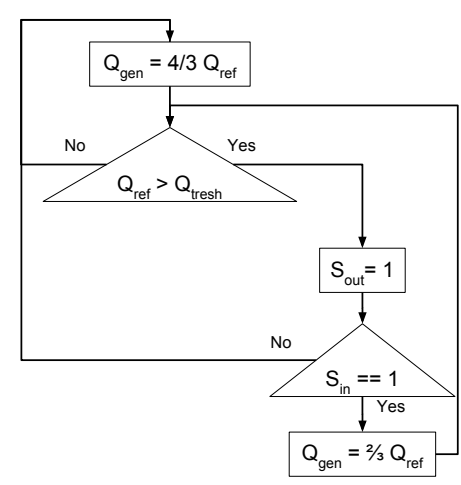

(a)

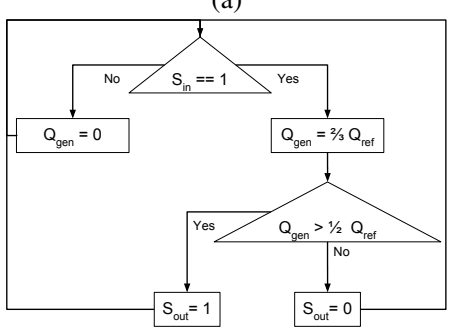

(b)

Fig. 7. Graphical representation of the reactive power compensation algorithm. (a) PV-side. (b) Wind-side.

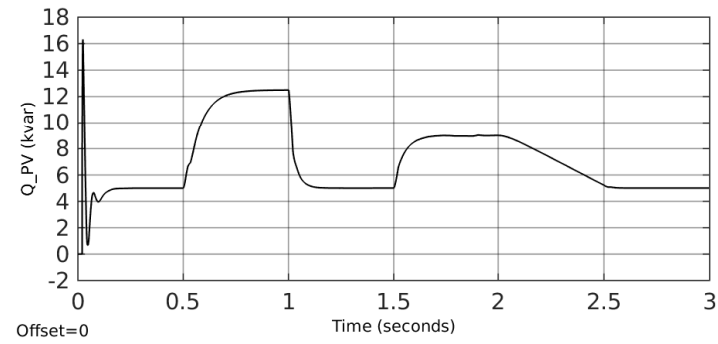

(a)

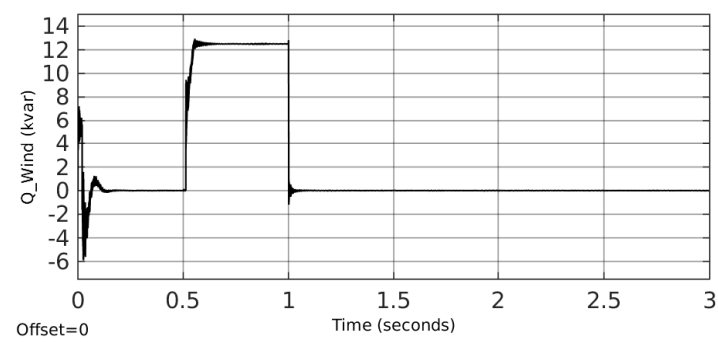

(b)

Fig. 8. Reactive power generation without communication disturbances. (a) PV system. (b) Wind turbine.

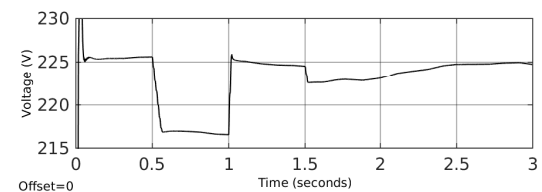

Fig. 9. $V_{\text {load }}$ without communication disturbances.

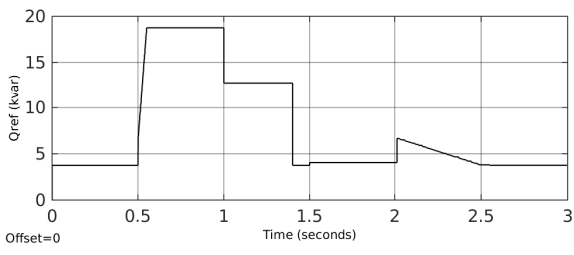

Fig. 10. $Q_{\text {ref }}$ received by the generation units.

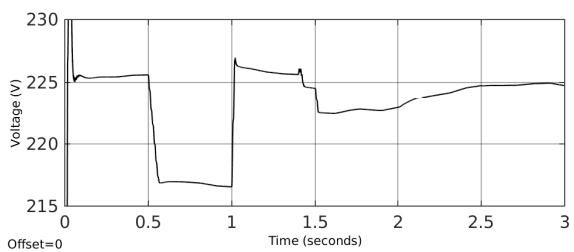

Fig. 11. Vload with communication disturbances.

\section{B. Disturbances on the reactive power reference link}

If the channel used to communicate the reactive power reference, is disturbed, it will affect the performance of the electrical grid. Due to the retransmissions mechanism in GOOSE, a considerable effect is obtained, only at high rates of packet loss. In Fig. 10 the value of $Q_{r e f}$ received by the PV system and the wind turbine, at a packet loss probability of 0.9 , is shown. By comparing this figure with the reactive power part of Fig. 5, which is the power reference sent, it is clear that the received $Q_{r e f}$ is not correct between second 1 and 2. So, reactive power generation profiles will be different, which results in a slightly different voltage profile (Fig. 11).

\section{Heavily loaded grid}

In the previous simulations, the properties of the electrical grid were based on real-life urban distribution grid configurations. As a result, lines were fairly short and oversized. These assets are advantageous, if the voltage drop is considered as reference for a well functioning grid. In order to consider a less favourable case, in the following simulation a distribution grid, whose line lengths are doubled compared to the previous cases, is considered.

To show the importance of communication, $V_{\text {load }}$ is measured, both with and without the communication network functioning. The result of these simulations is shown in Fig. 12. This figure shows the voltage profile in both cases. The French grid codes related to LV admissible variations are \pm 0.1 p.u. [14]. As seen in the figure, the inferior admissible boundary was crossed in the case of a non-functioning communication network. These results show that the effect of communication failure on the electrical network can be severe, since crossing of these boundaries should be avoided.

In order to identify the probability of packet loss $\left(P_{l o s s}\right)$ at which the voltage variation boundary is crossed, the simulations were run repeatedly with an increasing value of $P_{\text {loss }}$. By plotting the maximum voltage drop at the load, in function of this packet loss chance, Fig. 13 is obtained. By linear interpolation the value of $P_{\text {loss }}$, where the boundary is crossed, 


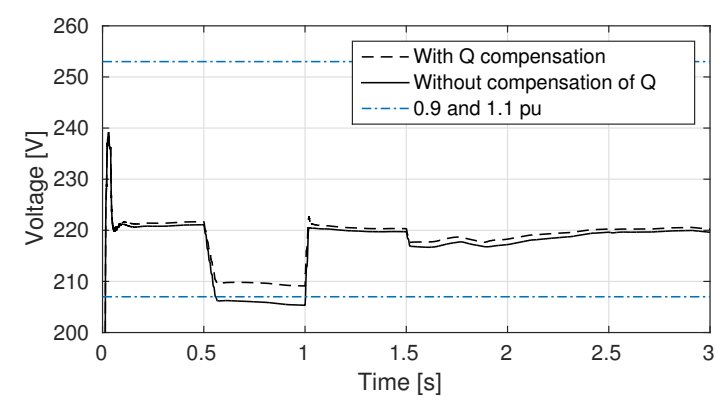

Fig. 12. $V_{\text {load }}$ with and without communication network.

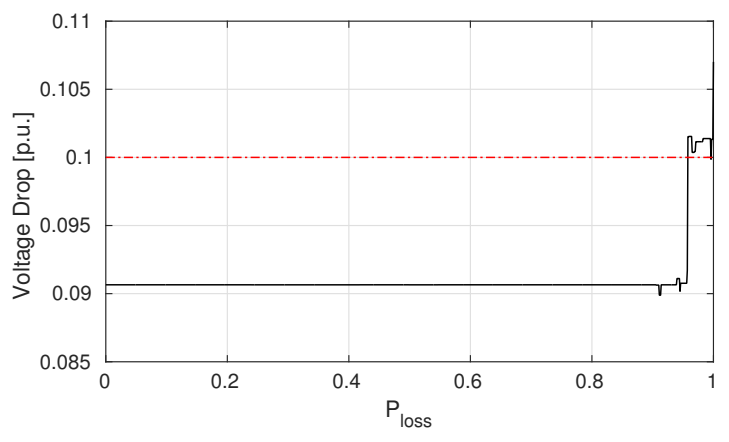

Fig. 13. $V_{\text {load }}$ drop in function of packet loss probability $\left(P_{\text {loss }}\right)$.

is determined to be 0.9580 . Increasing chances of packet loss can sometimes lead to lower voltage drops, since non-received packets might lead to reactive power over-compensation.

\section{CONCLUSION AND FurTher WORK}

A smart grid consisting of two grids, one that allows electrical energy to flow and the other one that allows data to be transmitted, has been considered in this paper. In a highly automated electrical grid both of them are important and one cannot work without the other. MATLAB ${ }^{\circledR} /$ Simulink $^{\circledR}$ cosimulation results obtained here showed a direct influence of the performance of the communication network on the electrical grid. Packet loss on different communication links have various effects, which cannot always be treated lightly; especially when the grid is heavily loaded, and has a rather rural than urban nature, the consequences can be as severe as crossing the grid codes adopted for safe operation of a distribution grid. In less critical cases, the behaviour of electrical dynamics in response to malicious events in the communication network was less destructive.

The co-simulation of an electrical grid together with a communication network is required to understand all their mutual interdependencies. The main goal of the work in this paper was to provide a starting point for designing a simulation combining both above mentioned systems. To this end, some simplifications were made in the progress. One of them concerns the reactive power control algorithm. One can expect that some more complex algorithms have a better performance. Other simplifications concern the GOOSE com- munication protocol, whose model implemented here is based on the most relevant of its numerous features. Other functions, like dynamic subscription of IEDs, could be implemented. In real-life situations there is also vertical communication. In the IEC 61850 standard, this data would run over TCP/IP in the form of MMS packets, which may also be prone to errors and may affect the functioning of the electrical grid.

In order to fully describe the consequences of disturbances, the work must be continued with expanded simulation models, allowing thorough mathematical modelling.

\section{REFERENCES}

[1] F. Andrén, R. Bründlinger, and T. Strasser, "IEC 61850/61499 control of distributed energy resources: Concept, guidelines, and implementation," IEEE Trans. on Energy Conversion, vol. 29, no. 4, pp. 10081017, Dec. 2014, ISSN: 0885-8969. DOI: 10.1109/TEC.2014.2352338.

[2] W. Li, M. Ferdowsi, M. Stevic, A. Monti, and F. Ponci, "Cosimulation for smart grid communications," IEEE Trans. on Industrial Informatics, vol. 10 , no. 4, pp. 2374-2384, Nov. 2014, ISSN: 1551-3203. DOI: 10. 1109/TII.2014.2338740.

[3] E. Sharma, A. I. Bratcu, C. Chiculita, and Y. Besanger, "Co-simulation of a low-voltage utility grid controlled over IEC 61850 protocol," in 2015 5th International Conference on Electric Utility Deregulation and Restructuring and Power Technologies (DRPT), Nov. 2015, pp. 23652372. DOI: 10.1109/DRPT.2015.7432642.

[4] D. Bian, M. Kuzlu, M. Pipattanasomporn, S. Rahman, and Y. Wu, "Real-time co-simulation platform using OPAL-RT and OPNET for analyzing smart grid performance," in 2015 IEEE Power \& Energy Society General Meeting, 2015, ISBN: 978-1-4673-8040-9. DOI: 10. 1109/PESGM.2015.7286238

[5] A. S. Masoum and A. Nejatian, "Power system management using wide area network digital control," in Power Engineering Conference (AUPEC), 2014 Australasian Universities, Sep. 2014, pp. 1-4. DOI: 10.1109/AUPEC.2014.6966623.

[6] V. Calderaro, V. Galdi, F. Lamberti, and A. Piccolo, "Coordinated local reactive power control in smart distribution grids for voltage regulation using sensitivity method to maximize active power," $J$. Electrical Systems, vol. 9, no. 4, pp. 481-493, Dec. 1, 2013. [Online]. Available: http://journal.esrgroups.org/jes/papers/9_4_8.pdf (visited on 03/15/2016).

[7] A. Keane, L. F. Ochoa, E. Vittal, C. J. Dent, and G. P. Harrison, "Enhanced utilization of voltage control resources with distributed generation," IEEE Trans. on Power Systems, vol. 26, no. 1, pp. 252-260, Feb. 2011, ISSN: 0885-8950. DOI: 10.1109/TPWRS.2009.2037635.

[8] K. Tanaka, M. Oshiro, S. Toma, A. Yona, T. Senjyu, T. Funabashi, and C. H. Kim, "Decentralised control of voltage in distribution systems by distributed generators," IET Generation, Transmission and Distribution, vol. 4, no. 11, pp. 1251-1260, Nov. 2010, ISSN: 17518687. DOI: $10.1049 /$ iet-gtd.2010.0003.

[9] C. Kriger, S. Behardien, and J.-C. Retonda-Modiya, "A detailed analysis of the generic object-oriented substation event message structure in an IEC 61850 standard-based substation automation system," Intl. Journal of Computers Communications \& Control, vol. 8, no. 5, p. 708, 2013, ISSN: 1841-9836. DOI: 10.15837/ijccc.2013.5.329.

[10] C. Fernandes, S. Borkar, and J. Gohil, "Testing of goose protocol of IEC61850 standard in protection IED," Intl. Journal of Computer Applications, vol. 93, no. 16, pp. 30-35, 2014, ISSN: 0975-8887. DOI: 10.5120/16301-6112.

[11] A. Cochet-Muchy, "IEC 61850 - advanced," Grenoble, Nov. 2013.

[12] SIEMENS, Latency on a switched ethernet network. [Online]. Available: http://w3 . siemens .com/mcms/industrial - communication/en/ rugged-communication/documents/an8.pdf (visited on 03/26/2016).

[13] (Oct. 9, 2012). Grid-connected PV array - file exchange - MATLAB central, [Online]. Available: http://fr.mathworks.com/matlabcentral/ fileexchange/34752-grid-connected-pv-array (visited on 03/20/2016).

[14] ERDF, Principes d'étude et de développement du réseau pour le raccordement des clients consommateurs et producteurs BT, Mar. 1, 2011. [Online]. Available: http://www.enedis.fr/sites/default/files/ documentation/ERDF-PRO-RES_43E.pdf. 